\title{
Teaching breast ultrasound skills including core-needle biopsies on a phantom enhances undergraduate student's knowledge and learning satisfaction
}

\author{
G. Schmidt ${ }^{1} \oplus \cdot$ C. Gerlinger ${ }^{1} \cdot$ J. Endrikat ${ }^{1} \cdot$ L. Gabriel $^{1} \cdot$ C. Müller ${ }^{1} \cdot$ S. Baus ${ }^{1} \cdot$ T. Volk $^{1} \cdot$ Sebastian Findeklee $^{1,2}$. \\ E. F. Solomayer ${ }^{1} \cdot$ A. Hamza ${ }^{1,3} \cdot$ R. Ströder ${ }^{1}$
}

Received: 12 October 2020 / Accepted: 23 February 2021 / Published online: 16 March 2021

(c) The Author(s) 2021

\begin{abstract}
Purpose To investigate whether a training program on breast ultrasound skills including core-needle biopsies to undergraduate students can improve medical knowledge and learning satisfaction.

Methods Medical students attending mandatory classes at the Medical School of the University of Saarland received a supplemental theoretical and hands-on training program on ultrasound (US) breast screening and on US-guided core-needle biopsy using an agar-agar phantom. Experienced breast specialists and ultrasound examiners served as trainers applying Peyton's 4-step training approach. The students' theoretical knowledge and hands-on skills were tested before and after the training program, using a multiple-choice questionnaire (MCQ), the Objective Structured Clinical Examination (OSCE) and a student curriculum evaluation.

Results The MCQ results showed a significant increase of the student's theoretical knowledge $(50.2-75.2 \%, p<0.001)$. After the course, the OSCE showed a mean total of $17.3 / 20$ points (86.5\%), confirming the practical implementation of the new skills. The student curriculum evaluation in general was very positive. A total of 16/20 questions were rated between 1.2 and 1.7 (very good) and 3 questions were rated as 2.1 (good).

Conclusion Undergraduate student's medical education can be enhanced by teaching breast US skills.
\end{abstract}

Keywords Breast ultrasound $\cdot$ Teaching $\cdot$ Undergraduate $\cdot$ Peyton $\cdot$ Core-needle biopsy

\section{Introduction}

Ultrasound (US) is widely used in diagnostic medicine as it is non-invasive, painless, fast $\&$ easy to perform, inexpensive and does not apply ionizing radiation [1]. It provides accurate images of tissue structures and offers valuable diagnostic information. US is used in almost every sub-specialty of obstetrics and gynecology, e.g., fetal medicine, general and specialized gynecology and senology $[2,3]$.

G. Schmidt

gilda.schmidt@uks.eu

1 Department of Gynecology, Obstetrics and Reproductive Medicine, University Medical School of Saarland, Kirrberger Straße, 66421 HomburgSaar, Germany

2 MVZ Fertility Center Hamburg, 20095 Hamburg, Germany

3 Department of Gynecology, Obstetrics, Kantonsspital Baden AG, 5404 Baden, Switzerland
While US devices are widely used the quality of the devices and the experience of the examiners vary widely. Both factors are key for accurate diagnosis. The examiner must be well-trained and have a deep knowledge of anatomy, physiology and pathology in order to be able to correlate US findings with clinical findings [4].

Today, most undergraduate students passively watch US examinations during their practical training, as available time of the experts and the number of patients willing to take part are limited. Therefore, US screening is not usually included in the undergraduate curriculum. Furthermore, USguided core-needle biopsy is an essential diagnostic tool for the evaluation of breast lesions [5, 6, 7].

In Germany, breast US training and certification is governed by the German Society of Ultrasound in Medicine (DEGUM). US examiners are classified according to their experience, training and certification into three levels [8]. In order to motivate future clinicians, the society included undergraduate education in their training programs [9]. The 
ability to use US as a diagnostic and interventional tool is an important complement to basic clinical skills $[4,10,11,12]$.

Training on phantoms increases the students' confidence and mitigates mistakes [13].

The goal of this study was to assess the effectiveness of an extended US breast training program on the knowledge and hands-on skills of undergraduate medical students.

Similar projects were successfully performed in obstetrics [11] and anesthesiology [14].

\section{Material and methods}

The participating students attended the 5th clinical semester. In addition to their mandatory practical training week in gynecology and obstetrics (which is part of the curriculum), this program was offered for particularly interested students. A total of 8-10 students formed a group, which were further divided in two groups for the practical training.

\section{Training program}

The training program encompassed $1 \mathrm{~h}$ of theoretical and $3 \mathrm{~h}$ of hands-on training. Prior to starting both training sessions, the student's knowledge was assessed with a baseline test of 15 multiple choice questions (MCQ). The increase in knowledge was tested approx. $5 \mathrm{~h}$ afterwards applying the same set of MCQ again. However, the answers have not been discussed and reviewed after the initial test so that the difference pre- vs. post-training reflected the gain in knowledge achieved in the training. In addition, an "objective structured clinical examination" (OSCE) and a "student curriculum evaluation" were applied. (Fig. 1.).

In the theoretical session, students learned basics on breast US examination, in particular US features of benign and malignant lesions including the International Breast Imaging Reporting and Data System classification (BIRADS) [15].

In the hands-on session, students were instructed in the use of the US device for breast screening in patients and how to perform a US-guided core-needle biopsy on the training phantom (Figs. 2, 3).

The hands-on session applied Peyton's 4-step training approach for skills teaching [16], as reported Hamza A et al. [11]. These four steps were: Step 1: "Demonstrate": The trainer demonstrates the skill at a normal pace and without additional comments; Step 2: "Talk the trainee through": the trainer demonstrates the respective skill while describing each procedural sub-step in detail; Step 3: "Trainee talks trainer through": the trainer performs the skill for a third time, based on the sub-steps described to him by the trainee; Step 4: "Trainee does": the trainee performs the skill on his/ her own.

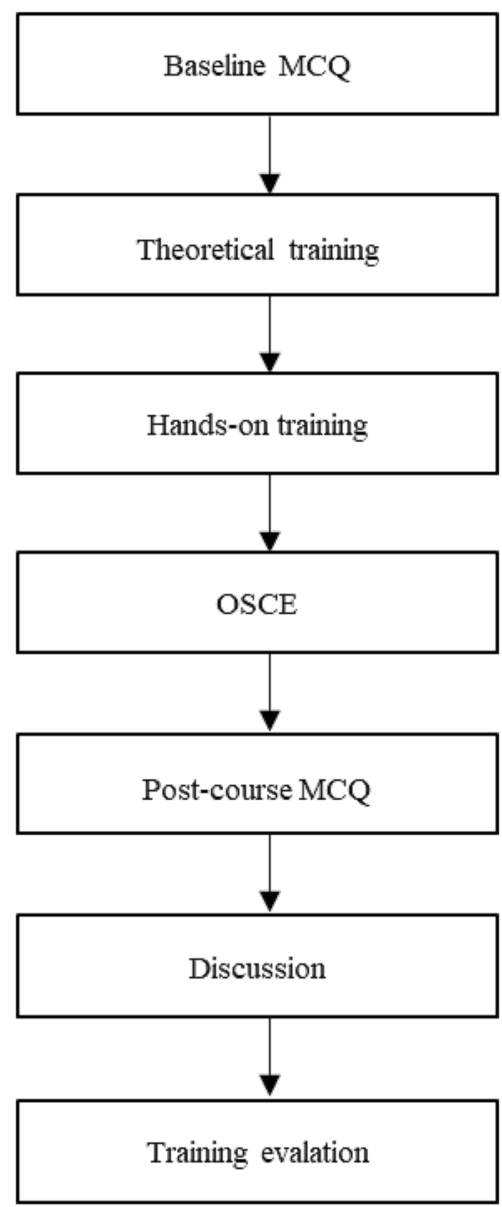

Fig. 1 Training program

The whole training program focused on the following skills: (1) DEGUM protocols for breast US screening; (2) scanning technique; (3) selection the correct US probe; (4) application of gel on patient; (5) adjustment of the image depth or contrast to optimize the visualization of the lesion; (6) setting of the focus point; (7) correct measurement of lesions; (8) freezing and printing the image; (9) visualization of core needle tip throughout the whole procedure; and (10) advancement of core needle tip into the lesion.

\section{Training phantom and US devices}

Students practiced the US-guided core-needle biopsy on an in-house-designed training phantom which looked like a "round pie" of black ink colored agar-agar gel, with several green olives floating inside, mimicking breast lesions (Fig. 2). Presence of olive material inside the biopsy needle confirmed a correct biopsy.

The US devices were Hitachi Preirus and Hitachi Ascendus. The biopsies were performed using BARD ${ }^{\circledR}$ MAGNUM $^{\circledR}$ biopsy system. 
Fig. 2 Training phantom made of agar-agar a Viewed from above (floating olives yellowish); $\mathbf{b}$ Viewed from the side
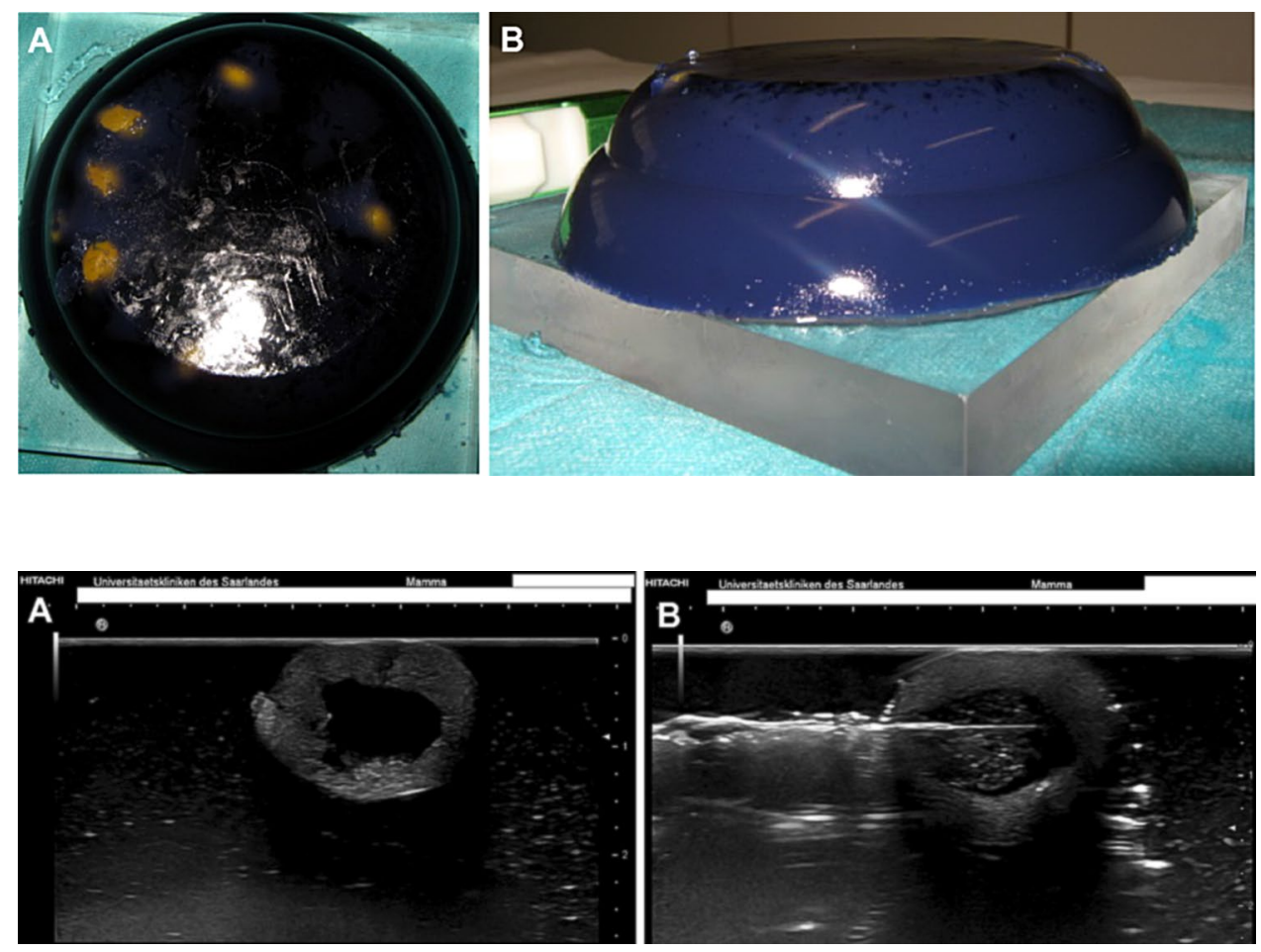

Fig. 3 Ultrasound image of training phantom with embedded green olives. a Before; $\mathbf{b}$ After core needle biopsy

\section{Knowledge evaluation}

\section{MCQ}

A total of 15 multiple choice questions (MCQ) were picked from the UCAN (Umbrella Consortium for Assessment Networks) questions pool about senology and breast US [17]. There were 12 questions on scientific background and three on image recognition.

For each single question, the null hypothesis that the proportion of right answers was equal before and after the course was tested using the Chi-square test. A summary score of the number of right answers was calculated per student and per time point. The null hypothesis that the total number of right answers was equal before and after the course was tested using the nonparametric Kruskal-Wallis test.

As appropriate for explorative analyses, a comparisonwise two-sided significance level of 5\% was used. The statistical analyses were performed using the package arsenal of the R (r-project.org) software.

\section{Objective structured clinical examination (OSCE)}

All students passed the Objective Structured Clinical Examination (OSCE). They were asked to examine an "imaginary subject" on two stations. On the "Ultrasound Station" they had to take the (1) medical history and (2) perform a clinical and ultrasound breast examination. On the "Punch Station" they had to obtain (3) a patient consent form and (4) perform an US-controlled core-needle biopsy on the agar-agar phantom. For each of the four categories 4-6 pre-defined requirements were scored with points. The maximum was 20 points.

\section{Student curriculum evaluation}

At the end of the training, the students were asked to evaluate the program using a standardized five-point scale questionnaire $(1=$ very good, $2=$ good, $3=$ satisfying, $4=$ adequate, $5=$ inadequate) on 20 questions (Table 3 ).

\section{Results}

A total of 40 students took part in the training program.

\section{MCQ}

The MCQ score increased significantly during the training from 7.5 to $11.3(p<0.001)$, as did the percentage of correct answers $(50.17-75.17 \%, p<0.001)$ (Table 1$)$.

Except for question \#5, the number of students with correct answers increased after the training (Fig. 4). 
Table 1 MCQ assessment before and after the training

\begin{tabular}{llll}
\hline MCQ & Before & After & $P$ value \\
\hline $\begin{array}{c}\text { Mean score } \\
\text { (range) }\end{array}$ & $7.5(2-12)$ & $11.3(5-15)$ & $<0.001$ \\
$\begin{array}{c}\text { Percentage }(\%) \\
\text { correct answers }\end{array}$ & $50.17 \%$ & $75.17 \%$ & $<0.001$ \\
\hline
\end{tabular}

OSCE

The results of the OSCE are shown in Table 2. The mean total was $17.3 / 20$ points $(86.5 \%)$, confirming the implementation of the new skills. The 4 categories (medical history, breast US, patient consent form and core-needle biopsy) were assessed individually. Students scored highest in patient's medical history $(97.5 \%)$ and lowest for core needle biopsy. All scores were $\geq 80 \%$ ) (Table 2).

\section{Student curriculum evaluation}

The student curriculum evaluation in general was very positive. A total of 16/20 questions were rated between 1.2 and 1.7 (very good) and three questions were rated $2.1 \mathrm{~s}$ (good).

Only one question about the requirements of the training program was rated as satisfying (3.0).

The most crucial questions "How do you rate the learning success of this program?", "Overall, how do you rate the program?" and "Would you recommend the program?" were very positive. All questions and liker scores are shown in Table 3.
Table 2 OSCE results after the training $(n=40)$

\begin{tabular}{llcl}
\hline & Achieved score & $\begin{array}{c}\text { Max. pos- } \\
\text { sible score }\end{array}$ \\
\hline Patients medical history & 3.9 & 4 & $97.50 \%$ \\
Breast US screening & 5.1 & 6 & $85.00 \%$ \\
Patient consent form & 3.5 & 4 & $87.50 \%$ \\
Core needle biopsy & 4.8 & 6 & $80.00 \%$ \\
Total & 17.3 & 20 & $86.50 \%$ \\
\hline
\end{tabular}

\section{Discussion}

This study assessed the effectiveness of an extended US breast training program on the knowledge and hands-on skills of undergraduate medical students. Students' knowledge increased, and students' satisfaction was high on completion of the course.

The results of the MCQ and the OSCE clearly showed that this supplemental training program provided value. The positive individual perception of the training was shown in the results of the student curriculum evaluation. Students particularly enjoyed the hands-on training part, using the US probe and performing core-needle biopsies on the phantom. They would recommend this program and similar learning opportunities to their fellow students.

Some other groups have reported on their experience in teaching US skills and US-guided core-needle biopsy to undergraduates. Limchareon $\mathrm{S}$ et al. showed the beneficial effect of a two-week rotation training in radiology on 48 student's US skills, regardless of their baseline performances. They also used the OSCE as a standardized assessment tool [18].
Fig. 4 Number of students with correct answers to 15 MCQs, before and after the training program

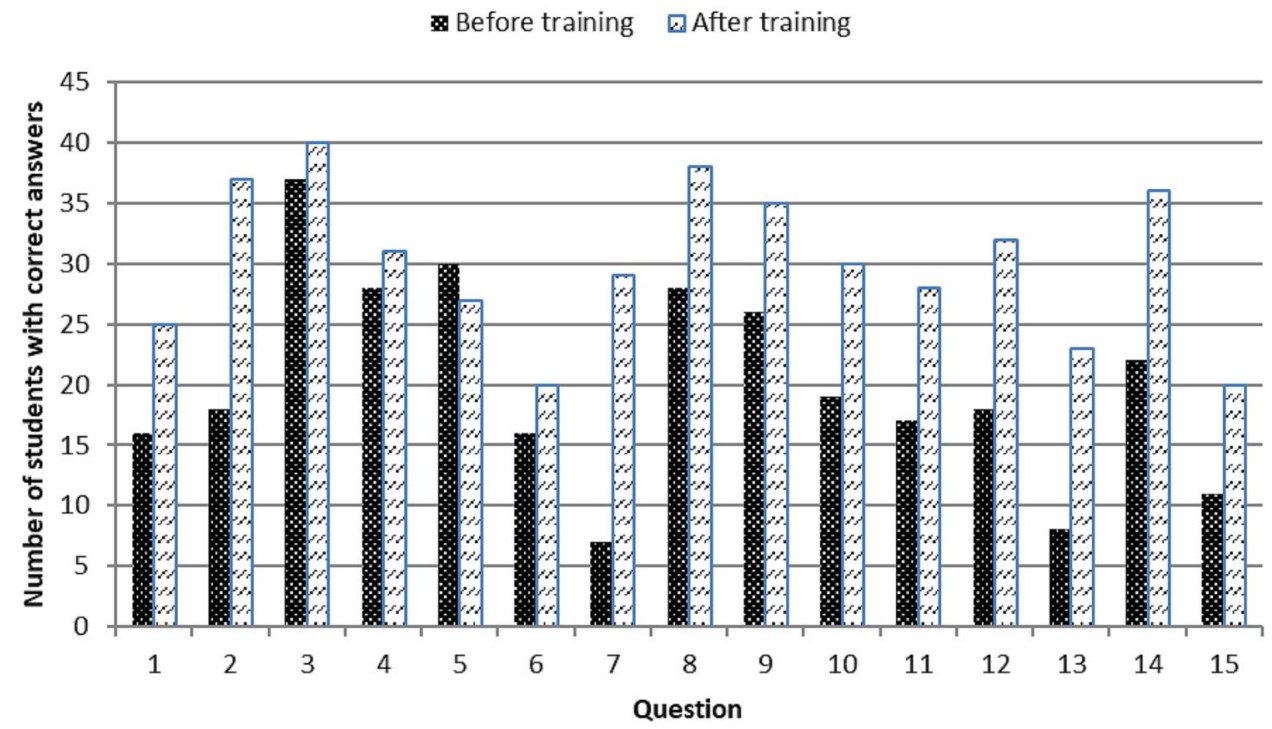


Table 3 Student curriculum evaluation questions expressed by mean liker scores

\begin{tabular}{ll}
\hline Question & Mean \\
\hline How well were the stated learning objectives defined? & 1.5 \\
How do you rate the quality of the classroom and the technical equipment? & 1.4 \\
How do you rate the punctuality and regularity of the course? & 1.4 \\
To what extent was the course understandable and clearly processed? & 1.5 \\
To what extent were medical/clinical references established? & 1.3 \\
To what extent were references made to current topics? & 1.7 \\
To what extent do you value the course as relevant to the exam? & 2.1 \\
How do you rate the quality of the teaching materials? & 1.6 \\
Were suggestions given for in-depth study? & 2.1 \\
How do you value the professional competence of the instructor? & 1.2 \\
How did you perceive the learning and working atmosphere? & 1.5 \\
How do you rate the motivation and preparation of the instructor? & 1.2 \\
Could you follow the instructor well? & 1.4 \\
Did the instructor repeat the content adequately? & 1.3 \\
How would you rate the opportunity to ask questions and the willingness to discuss? & 1.3 \\
How good was interdisciplinary teaching? & 2.1 \\
How do you rate the learning success of this course? & 1.5 \\
Overall, how do you rate the course? & 1.4 \\
How do you rate the requirements of the course for yourself? & 3.0 \\
Would you recommend the course? & 1.4 \\
\hline
\end{tabular}

Liker scores: 1 very good, 2 good, 3 satisfying, 4 adequate, 5 inadequate
Ault et al. performed a breast workshop focusing on physical examination, mammography and US interpretation. They stated that this workshop was more effective than the traditional outpatient setting for teaching clinical breast examination skills [19].

Hamza et al. [11] and Takacs et al. [20] reported similar positive results from comparable programs in other disciplines.

In this study an agar-agar training phantom was used for the core-needle biopsies. This is highly cost-effective (approx. 2 Euros per phantom) and allowed avoiding usage of fresh cadavers as proposed by McCrary $\mathrm{H}$ et al. [13] or fleshy tissue like turkey breast [21]. However, all these training models are for single use only. Another, more expensive option for US breast teaching purposes including biopsies is mannequin simulators. These simulators were already used for teaching obstetrical US by Chalouhi et al., who reported no differences between training results on the mannequin versus pregnant volunteers [22].

Young physician's education is key for the future of healthcare systems in order to offer highest standards in diagnosis and treatment. Currently, an update of undergraduate teaching is being developed in Germany (Masterplan 2020) with increased focus on hands-on trainings of medical students [23]. This will certainly require more teaching facilities. This study provides additional evidence for the effectiveness of this new teaching approach.
Some limitations need to be addressed: (1) The training phantom made of agar-agar does not realistically resemble the human breast; (2) The phantom can only be used for one training session; (3) This training program required a large time commitment from the teaching personal, and because of staff and budget constraints in many hospitals, might not yet be feasible in the routine setting [11].

\section{Conclusion}

Undergraduate student's medical education can be enhanced by teaching breast US skills.

Acknowledgement This article does not contain any studies with animals performed by any of the authors. The course was part of the medical education at the Medical School of the University of Saarland.

Author's contributions GS contributed to project development and manuscript writing. CG contributed to data analysis. JE was involved in manuscript editing and reviewing and support writing. LG, CM, $\mathrm{SB}, \mathrm{TV}, \mathrm{SF}$, and EFS contributed to manuscript reviewing. AH was involved in manuscript editing and reviewing. RS contributed to support project development and manuscript reviewing.

Funding Open Access funding enabled and organized by Projekt DEAL. 


\section{Declarations}

Conflict of interest None of the authors declared any conflict of interest. All authors are consent with the publication of the paper "Teaching breast ultrasound skills including core-needle biopsies on a phantom enhances undergraduate student's knowledge and learning satisfaction" in Archives of Gynecology and Obstetrics.

Informed consent Informed consent was obtained from all individual participants included in the study. The Local Ethics Committee (Ethikkommission der Ärztekammer des Saarlandes) approved the study.

Open Access This article is licensed under a Creative Commons Attribution 4.0 International License, which permits use, sharing, adaptation, distribution and reproduction in any medium or format, as long as you give appropriate credit to the original author(s) and the source, provide a link to the Creative Commons licence, and indicate if changes were made. The images or other third party material in this article are included in the article's Creative Commons licence, unless indicated otherwise in a credit line to the material. If material is not included in the article's Creative Commons licence and your intended use is not permitted by statutory regulation or exceeds the permitted use, you will need to obtain permission directly from the copyright holder. To view a copy of this licence, visit http://creativecommons.org/licenses/by/4.0/.

\section{References}

1. Rao S, van Holsbeeck L, Musial JL, Parker A, Bouffard JA, Bridge P, Jackson M, Dulchavsky SA (2008) A pilot study of comprehensive ultrasound education at the Wayne State University School of Medicine: a pioneer year review. J Ultrasound Med 27(5):745-749 (PubMed PMID: 18424650)

2. Campbell S (2013) A short history of sonography in obstetrics and gynaecology. Facts Views Vis Obgyn 5(3):213-229 (PMID: 24753947; PMCID: PMC3987368)

3. Levi S (1997) The history of ultrasound in gynecology 1950-1980. Ultrasound Med Biol 23(4):481-552. https://doi. org/10.1016/s0301-5629(96)00196-2 (PMID: 9232763)

4. Teichgräber UK, Meyer JM, Poulson Nautrup C, von Rautenfeld DB (1996) Ultrasound anatomy: a practical teaching system in human gross anatomy. Med Educ 30:296-298

5. NICE. The National Institute for Health and Care Excellence (NICE). Advanced breast cancer: diagnosis and treatment [Updated 2014]. https://www.nice.org.uk/guidance/cg81/evide nce/addendum-242246990. [Online] 2009.

6. Dahabreh IJ, Wieland LS, Adam GP, Halladay C, Lau J, Trikalinos TA (2014) AHRQ comparative effectiveness reviews, in core needle and open surgical biopsy for diagnosis of breast lesions: an update to the 2009 Report. Agency for Healthcare Research and Quality (US): Rockville (MD).

7. Interdisziplinäre S3-Leitlinie für die Früherkennung, Diagnostik, Therapie und Nachsorge des Mammakarzinoms, Langversion 4.3. https://www.leitlinienprogramm-onkologie.de/leitlinien/ mammakarzinom/. [Online] Feb 2020. AWMF-Registernummer: 032-045OL.

8. DEGUM. Mehrstufenkonzept and Zertifizierung. http://www. degum.de/sektionen/radiologie/mehrstufenkonzept-zertifizierung. html. [Online]

9. DEGUM. Angebote für Studenten. http://www.degum.de/angeb ote-fuer/studenten.html. [Online]
10. Blackstock U, Munson J, Szyld D (2015) Bedside ultrasound curriculum for medical students: report of a blended learning curriculum implementation and validation. J Clin Ultrasound 43(3):139-44. https://doi.org/10.1002/jcu.22224 (PubMed PMID: 25123564)

11. Hamza A, Solomayer EF, Takacs Z, Juhasz-Boes I, Joukhadar R, Radosa JC, Mavrova R, Marc W, Volk T, Meyberg-Solomayer G (2016) Introduction of basic obstetrical ultrasound screening in undergraduate medical education. Arch Gynecol Obstet 294(3):479-485. https://doi.org/10.1007/s00404-015-4002-9 (PMID: 26742729.)

12. Arger PH, Schultz SM, Sehgal CM, Cary TW, Aronchick J (2005) Teaching medical students diagnostic sonography. J Ultrasound Med 24(10):1365-9. https://doi.org/10.7863/jum.2005.24.10.1365 (PMID: 16179619)

13. McCrary HC, Krate J, Savilo CE, Tran MH, Ho HT, AdamasRappaport WJ, Viscusi RK (2016) Development of a fresh cadaver model for instruction of ultrasound -guided breast biopsy during the surgery clerkship: Pre-test and post -test results among third -year medical students. Am J Surg 212:1020-1025

14. Hüppe T, Groesdonk HV, Volk T, Wagenpfeil S, Wallrich B (2019) Image quality to estimate ventricular ejection fraction by last year medical students improves after short courses of training. BMC Med Educ 19(1):385. https://doi.org/10.1186/s12909-0191809-2 (PMID: 31640642; PMCID: PMC6805468)

15. Radiology AC (2013) Breast imaging reporting and data system atlas Breast Imaging Atlas. American College of Radiology, Reston

16. Walker M, Peyton JW (1998) Teaching in the Theatre. In: Teaching and Learning in Medical Practice. Heronsgate Rickmansworth, Herts.: Manticore Europe Ltd. S171-S180.

17. UCAN. https://www.ucan-assess.org/. [Online]

18. Limchareon S, Kongprompsuk S (2018) A single static breast model education of ultrasound skill in final year medical students of Burapha University. J Med Ultrasound. 26(3):143-146. https:// doi.org/10.4103/JMU.JMU_11_18 (Epub 2018 Sep 14. PMID: 30283200; PMCID: PMC6159323)

19. Ault GT, Sullivan M, Chalabian J, Skinner KA (2002) A focused breast skills workshop improves the clinical skills of medical students. J Surg Res 106(2):303-7. https://doi.org/10.1006/ jsre.2002.6472 (PMID: 12175983)

20. Takacs FZ, Solomayer EF, Hamza A, Juhasz-Böss I, Sklavounos P, Radosa JC, Findeklee S (2020) Conisation course for medical students-experience from a German University Hospital. J Turk Ger Gynecol Assoc 21(2):79-83. https://doi.org/10.4274/ jtgga.galenos.2019.2019.0126 (PMID: 31612696; PMCID: PMC7294840)

21. Sites BD, Gallagher JD, Cravero J, Lundberg J, Blike G (2004) The learning curve associated with a simulated with a simulated ultrasound-guided interventional task by inexperienced anesthesia residents. Reg Anesth Pain Med 29:544-548

22. Chalouhi GE, Bernardi V, Gueneuc A, Houssin I, Stirnemann JJ, Ville Y (2016) Evaluation of trainee's ability to perform obstetrical ultrasound using simulation: challenges and opportunities. Am J Obstet Gynecol 214(525):e1-8

23. Masterplan (2020) https://www.bmbf.de/de/masterplan-mediz instudium-2020-4024.html. [Online].

Publisher's Note Springer Nature remains neutral with regard to jurisdictional claims in published maps and institutional affiliations. 